\title{
Study of flow structure of the plasma torch for microwave plasma spray
}

\author{
Muhammad Fahmi Izuwan Samion'1,Nur Ziana Norizat ${ }^{1}$ and Ahmad Redza Ahmad Mokhtar1,* \\ ${ }^{1}$ Faculty of Manufacturing \& Mechatronic Engineering Technology, College of Engineering, Universiti Malaysia Pahang, 26600 Pahang, Malaysia.
}

\begin{abstract}
Microwave oven induced plasma method is a novel application of microwave oven to generate plasma for coating process. It uses $2.45 \mathrm{GHz}$ microwave power and only $0.8 \mathrm{~kW}$ input power to produce the plasma which capable of spraying all materials that are considered sprayable. However, the researches regarding this microwave plasma spray are more to be discovered. Suitable structure of plasma torch is needed for microwave plasma spray that can produce laminar flow to produce desire plasma for coating application. Therefore, this paper will discuss about the suitable structure of plasma torch needed for laminar flow by Reynolds number calculation. Reynolds number calculated by applying the outlet diameter of antenna which is 2, 3 and $4 \mathrm{~mm}$. From this research, Reynolds number from all outer diameter of antenna are below 2000 which indicate laminar flow. The widest plasma diameter achieved at $6.59 \mathrm{~mm}$ with $4 \mathrm{~mm}$ outlet diameter of antenna and $15 \mathrm{lpm}$ working gas flow rate while the narrowest plasma diameter achieved at 1.26 $\mathrm{mm}$ with $3 \mathrm{~mm}$ outlet diameter of antenna and $10 \mathrm{lpm}$ flow rates of working gas. The most acceptable condition for producing plasma plume was at $3 \mathrm{~mm}$ of antenna diameter with $25 \mathrm{lpm}$ of Ar gas flow rates.
\end{abstract}

ARTICLE HISTORY

Revised: $29^{\text {th }}$ September 2020

Accepted: $30^{\text {th }}$ September 2020

\section{KEYWORDS}

Microwave Plasma

Plasma Spray

Antenna Nozzle

\section{INTRODUCTION}

Coating is found almost anywhere in daily life and the development of coating technology grows every year. Thermal spraying is one of the most promising applications of coating technology. There are various types of thermal spray available today and the plasma spraying method is the most versatile of the thermal spray processes which capable of spraying all materials that are considered spray able. It uses thermal energy which caused by ignition of gas plume. It is also a surface modification treatment by adding new materials on the surface of substrates [1]. Microwave plasma is easy to be generated at low power with less than $1 \mathrm{~kW} \mathrm{[2]} \mathrm{and} \mathrm{has} \mathrm{stability} \mathrm{in} \mathrm{wide} \mathrm{range} \mathrm{of} \mathrm{pressure} \mathrm{[3]}$

The are many factors affecting the plasma spray coating process such as spray stream, material feed, gun and substrate [3]. In this research we focus more on the flow of the spray stream and the antenna nozzle design. Flow rate of carrier gas is a main thing for improving the quality of coating that can be achieved through plasma spray coating by using microwave plasma spray. The flow velocity on the plasma generation process can be evaluate in terms of the Reynolds number, which distinguish the flow as a laminar flow or a turbulent flow. The Reynolds number is defined for several different situations in which a fluid is in relative motion to the inner surface of the tube. Under ordinary conditions, it has been found that the flow is always laminar for Reynolds numbers of less than 2000 [4]. Basically, plasma plume will be form by generating non thermal gas species that will make it a flow of gas plasma by a provided device. In the recent experiment of plasma jet, it said that when the gas flow rate is higher than the critical Reynolds number, which seems to be related to the turbulence fluctuations significantly. In their report, the length of Ar-plasma plume shows to be shortened, when the critical Reynolds number is over 2320 [5].

This paper is discussing on Reynolds number application in structure of the plasma torch for microwave plasma spray. Suitable structure of plasma torch needed for laminar flow by Reynolds number calculation. However, the research concerning this microwave plasma spray is very less and the mechanisms are still more to be ascertained different antenna outlet diameter and gas working flow rate by using same output power which is $0.8 \mathrm{~kW}$ are used in this experiment. This different in antenna outlet diameter and gas flow rates will give us different value of calculated Reynolds which plays importance part in this investigation.

\section{METHODOLOGY}

The methodology in this paper is separated in two major components, which are process design and experimental setup. Design process was using (SHARP, R213CST) microwave oven and brass pipe as a nozzle antenna while the experimental setup was conducted for Reynolds number calculation.

\section{Process Design}

Fig. 1 shows the designated schematic diagram of the microwave oven plasma spray device used in this study. The antenna which made of copper metal pipe were positioned on the centre axis of the microwave oven cavity to utilize the 
concentration of microwave electric field [6]. Besides, we placed the antenna vertically to support with gravitational force. The present of quartz tube will affect the plasma plume volume, plume length and discharge current [7]. Quartz tube is transparent to microwaves environment. By that, working gas which is argon flows through a quartz tube can be ionized by microwaves [8]. Quartz tube functioned as a reaction cavity for plasma plume. The discharge tube's material is compulsory due to the shift of resonance frequency. The shift happens due to the material's dielectric constant itself [9]. The function of the dummy load is to avoid any reflected return to microwave generator. It will also reduce the possibility of arcing inside microwave oven cavity [10].

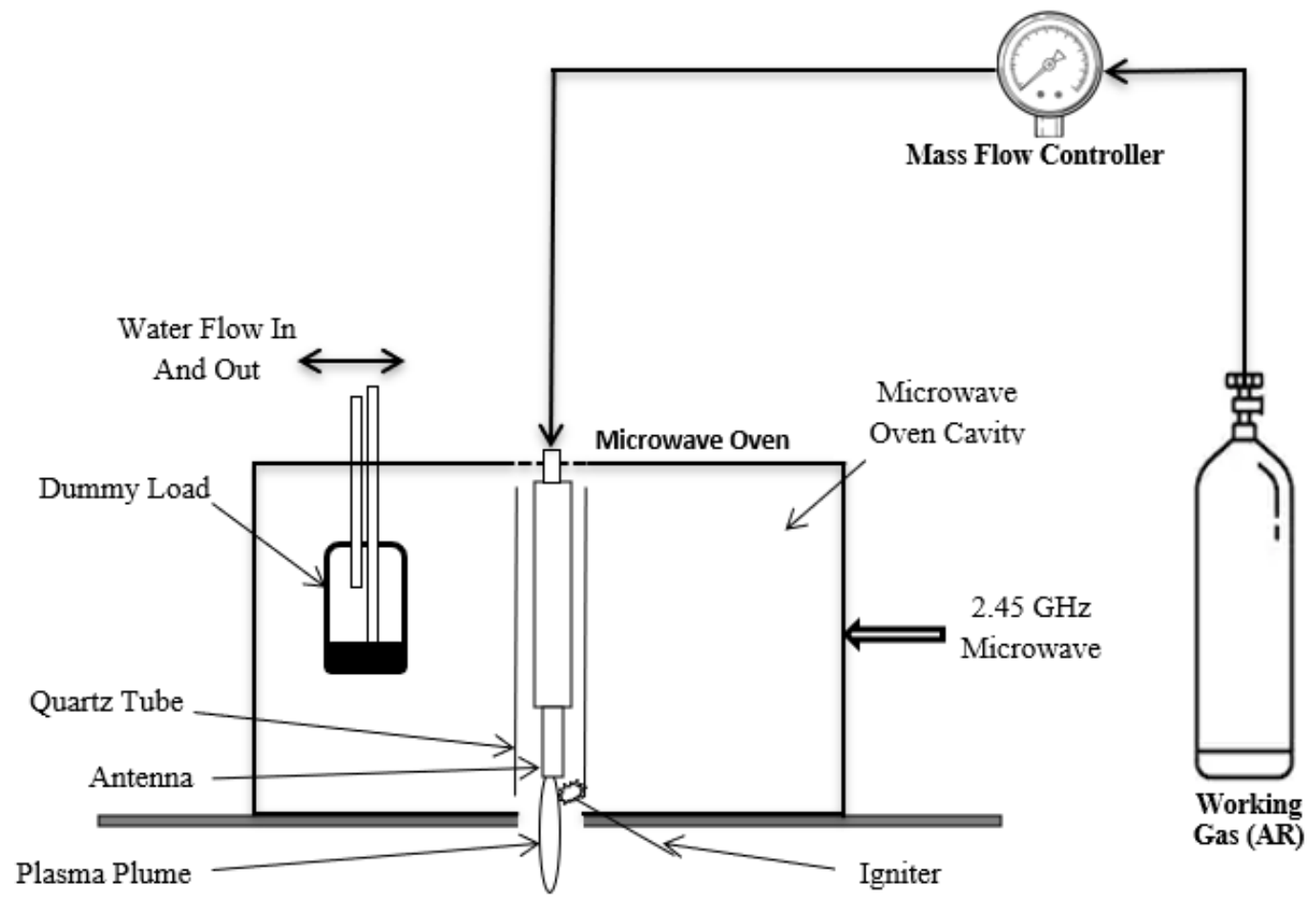

Fig. 1 Schematic diagram of the microwave oven plasma spray device

\section{Experimental Setup}

\section{Plasma Ignition}

This investigation of the plasma ignition condition for the microwave oven induced plasma is conducted in this experiment. The experimental condition of plasma ignition of induced plasma is shown in Table 1. The operations time is limited until 210 seconds to minimize the damage taken by the antenna. The images of the plasma plume produce were taken by camera and will be analysing using image processing method. For the power supply, output source is used that produce by microwave oven itself. While for the carrier gas fixed to Argon. Argon is selected because it is inert gas which easy for ionization for generating plasma.

\begin{tabular}{ll}
\multicolumn{2}{l}{ Table 1. Experimental condition for plasma ignition } \\
\cline { 2 - 3 } Condition & Value \\
\hline Antenna Outlet Diameter $(\mathrm{mm})$ & $2,3,4$ \\
Working Gas Flow Rate $(1 / \mathrm{min})$ & $10,15,20,25$ \\
Output Power $(\mathrm{kW})$ & 0.8 \\
Working Gas & Argon \\
\hline
\end{tabular}

\section{Reynolds number calculation}

Experiment conducted to analyse the data using Reynolds number formula. The data that need to be implemented are carrier gas flow rate, outlet diameter (OD) of antenna nozzle and temperature of plasma during ignition. The Reynolds number $(\mathrm{Re})$ will indicate whether the flow is laminar or turbulence. The experimental condition is shown in Table 1.

The stability of plasma can be determined by outlet diameter of antenna and working gas flow rate. The effect of the gas flow velocity in stable plasma production can be interpreted by Reynolds number. Reynolds number will indicate whether the flow is laminar or turbulence. In this contact, laminar flow is the best decision for plasma formation state. In order to get Reynolds number, equation (1) for volume flow rate formula, (2) for energy balance in open system and (3) for Reynolds number formula to be applied. Table 2 shows the type of flow by Reynolds number. 


$$
\begin{aligned}
& V_{1}=\frac{4 \dot{V}}{\pi D_{1}^{2}} \\
& h_{1}+\frac{V_{1}^{2}}{2} \dot{m}+\dot{m} g z_{1}=h_{2}+\frac{V_{2}^{2}}{2} \dot{m}+\dot{m} g z_{2} \\
& R e=\frac{\rho_{2} V_{2} D_{2}}{\mu_{2}}
\end{aligned}
$$

Table 2. Type of flow by Reynolds number

\begin{tabular}{ll}
\hline Reynolds number, $\mathrm{Rn}$ & Type of flow \\
\hline $\mathrm{Rn}<2000$ & Laminar \\
$2000<\mathrm{Rn}<4000$ & Transition \\
$\mathrm{Rn}>4000$ & Turbulent \\
\hline
\end{tabular}

\section{RESULT AND DISCUSSION}

\section{Plasma Ignition}

The experimental result for plasma ignition condition is shown in Table 3. All working gas flow rate are able to generate plasma and the width of the plasma plume increase when the increasing of the flow rate of the Ar is shown in Fig.2. It can be seen that the different the size of antenna diameter and different gas flow rate used, the different the length and width of plasma plume produced.

Thermal pinching effect which play important role for the plasma shape of the velocity profile in the nozzle antenna can be observed start at $15 \mathrm{lpm}$ of flow rates [11]. In addition, the length of plume only is affected by changing the gas flow rate of $\mathrm{Ar}$ [12]. On the other hand, the increasing of gas flow rate cause shape of plasma becomes narrower.

Moreover, it can be clarified that the influence of amount of water inside the dummy load for plasma generation effect the generation of plasma. Flowing of water is suitable enough for reducing concentration of microwave energy to generate the plasma. Thus, the sufficient microwave field heated the electrons, where the electric field was further concentrated with the emergence of the argon gas.

Table 3 Experimental result for plasma ignition at 2, 3 and 4mm antenna OD

\begin{tabular}{lllll}
\hline $\begin{array}{l}\text { Antenna } \\
\text { Outlet } \\
\text { Diameter }\end{array}$ & $10 \mathrm{lpm}$ & \multicolumn{3}{c}{ Gas Flow Rates } \\
\hline $2 \mathrm{~mm}$ & & & & \\
\hline
\end{tabular}




\section{Width of plasma plume}

Based on graph shown in Fig. 2 below, it can be concluded that the widest plasma diameter achieved at $6.59 \mathrm{~mm}$ with $4 \mathrm{~mm}$ outlet diameter of antenna and $15 \mathrm{lpm}$ working gas flow rate. While the narrowest plasma diameter achieved at $1.26 \mathrm{~mm}$ with $3 \mathrm{~mm}$ outlet diameter of antenna and $10 \mathrm{lpm}$ flow rates of working gas. For $2 \mathrm{~mm}$ outlet diameter of antenna, the width of plasma plume got fluctuated trend. At $10 \mathrm{lpm}$ the width become the widest among themselves. Then, it declines at $15 \mathrm{lpm}$ and $20 \mathrm{lpm}$. After faced the reduction, it increases slightly at $25 \mathrm{lpm}$. Then for $3 \mathrm{~mm}$ outlet diameter of antenna, increment of width of plasma plume affected by increment of working gas flow rate. Next, for 4 mm outlet diameter of antenna, the trend is opposite to $2 \mathrm{~mm}$ outlet diameter of antenna. At $10 \mathrm{lpm}$, it got narrow width of plasma plume and started rise at $15 \mathrm{lpm}$ and $20 \mathrm{lpm}$. Then at $25 \mathrm{lpm}$, it got the narrowest width of plasma plume among themselves.

From observation when undergoing the experiment, the most stable condition for producing plasma plume was at $3 \mathrm{~mm}$ of antenna diameter with $25 \mathrm{lpm}$ of Ar gas flow rates. Its stability observes by its good shape of plasma plume at condition stated. It can be said that the steady trend length of plasma plume over the working gas flow rate at $3 \mathrm{~mm}$ outlet diameter of antenna effect its stable condition of plasma.

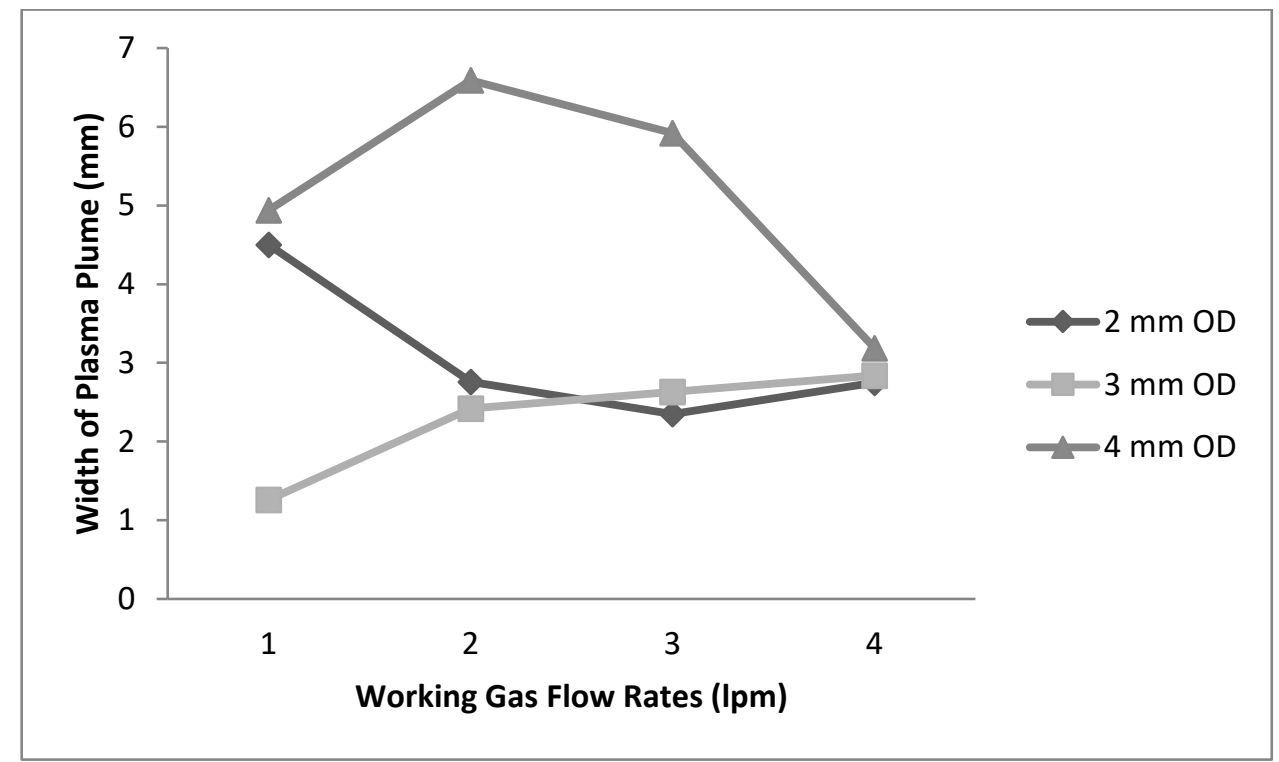

Fig. 2 Width of plasma plume by the change of working gas flow rate and OD

\section{Study flow from Reynolds number calculation}

Reynolds number calculated by applying the outlet diameter of antenna which is 2, 3 and $4 \mathrm{~mm}$. From the result shown in Fig. 3, Reynolds number from all outer diameter of antenna are below 2000 which indicate laminar[13]. The plasma shows more stable discharge when laminar flow take place rather than turbulence flow [4]. Due to high plasma temperature in the central region, plasma got high molecular velocity and results by small Reynolds number [4]. The gas particle will move in straight line when undergo laminar flow.

The range of Reynolds number between 2000 and 4000 is described as the transition which known as critical region because of unpredicted flow. One should avoid using this type of flow in this range. When Reynold number exceeds 4000, the flow will change into turbulence flow which characterized by irregular movement flow of the particle. Thus, it can be concluded that all OD are applicable for plasma ignition since they have laminar flow. 


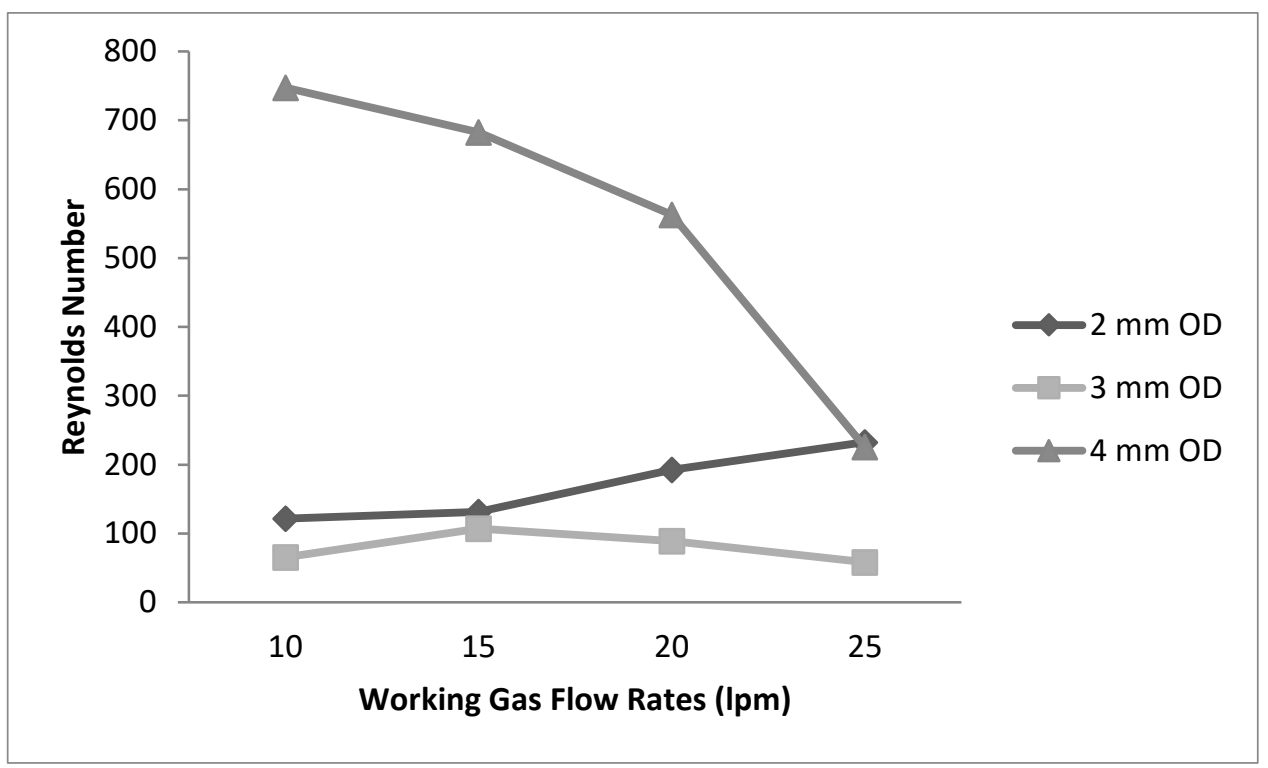

Fig. 3 Calculated Reynolds number by the change of working gas flow rate and OD

\section{CONCLUSION}

This paper reports that calculated Reynolds number from 2, 3 and 4mm OD of antenna below 2000 which indicate laminar flow. Width of plasma influenced by change of working gas flow rates and OD of antenna. this microwave plasma spray application can be used for coating the material and produce at low power, suitable for low melt substrate such as plastic, polymer and resin.

\section{ACKNOWLEDGEMENT}

The authors gratefully appreciated University Malaysia Pahang for the financial support through Internal Research Grant RDU1703255.

\section{REFERENCES}

[1] J.R. Davis, Surface Engineering for Corrosion and Wear Resistance, vol. 51, no. 1. ASM International, 2001.

[2] T. Yasui, A. R. Ahmad Mokhtar, and M. Fukumoto, "Development of Low Power Plasma Spray Process Using Atmospheric Pressure Microwave Plasma," May 2013.

[3] A. Redza, "Study on operational characteristics of low power atmospheric pressure microwave plasma spray method," Doctor of Engineering AHMAD REDZA BIN AHMAD MOKHTAR Toyohashi University of Technology," Toyohashi University of Technology, 2016.

[4] D. J. Jin, H. S. Uhm, and G. Cho, "Influence of the gas-flow Reynolds number on a plasma column in a glass tube," Phys. Plasmas, vol. 20, no. 8, p. 083513, Aug. 2013, doi: 10.1063/1.4819246.

[5] S. Wu, Z. Wang, Q. Huang, X. Tan, X. Lu, and K. Ostrikov, "Atmospheric-pressure plasma jets: Effect of gas flow, active species, and snake-like bullet propagation," Phys. Plasmas, vol. 20, no. 2, 2013, doi: 10.1063/1.4791652.

[6] M. Leins, S. Gaiser, A. Schulz, M. Walker, U. Schumacher, and T. Hirth, "How to Ignite an Atmospheric Pressure Microwave Plasma Torch without Any Additional Igniters," J. Vis. Exp., no. 98, Apr. 2015, doi: 10.3791/52816.

[7] J. Song et al., "Contrasting Characteristics of Atmospheric Pressure Cold Plasma Jets With Different Tube Materials," IEEE Trans. Plasma Sci., vol. 44, no. 11, pp. 2564-2567, 2016, doi: 10.1109/TPS.2016.2546548.

[8] W. Toor, A. U. Baig, N. Goraya, R. Irfan, and M. Ashraf, "Atmospheric Pressure Microwave Plasma System and Its Applications," no. June, 2018.

[9] F. Bozduman, A. Gulec, T. Aktan, and L. Oksuz, "Atmospheric pressure microwave plasma torch,” 2011, pp. 1-1, doi: 10.1109/plasma.2011.5993179.

[10] D. J. Brooks and R. E. Douthwaite, "Microwave-induced plasma reactor based on a domestic microwave oven for bulk solid state chemistry," Rev. Sci. Instrum., vol. 75, no. 12, pp. 5277-5279, 2004, doi: 10.1063/1.1821623.

[11] A. Redza, T. Yasui, and M. Fukumoto, "Deposition of Hard Chrome Coating onto Heat Susceptible Substrates by Low Power Microwave Plasma Spray,” IOP Conf. Ser. Mater. Sci. Eng., vol. 114, no. 1, p. 012030, 2016, doi: 10.1088/1757899X/114/1/012030.

[12] L. M. D. Rosario et al., "Characterization of a Microwave-Induced Atmospheric-Pressure Ar-N2 Plasma Pencil," IEEE Trans. Plasma Sci., vol. 45, no. 2, pp. 301-309, 2017, doi: 10.1109/TPS.2016.2638833.

[13] M. F. Izuwan, A. Redza, and M. Nizar, "Study on Operational Characteristic of Microwave Oven Driven Plasma Spray Device," in iMEC-APCOMS 2019, M. N. Osman Zahid, R. Abd. Aziz, A. R. Yusoff, N. Mat Yahya, F. Abdul Aziz, and M. Yazid Abu, Eds. Singapore: Springer Singapore, 2020, pp. 558-563. 